\title{
Effects of Scopolamine on Matching to Sample Paradigm and Related Tests in Human Subjects
}

\author{
G. Koller W. Satzger M. Adam M. Wagner \\ R. Engel \\ Department of Psychiatry, University of Munich, Munich, Germany
}

\author{
N. Kathmann M. Soyka
}

\section{Key Words}

Scopolamine $\cdot$ Matching to sample $\cdot$ Memory $\cdot$ Attention

\begin{abstract}
This was a double-blind placebo-controlled study with a cross-over design to examine the effects of scopolamine on cognitive functions in young healthy subjects. Scopolamine hydrobromide was administered subcutaneously to 12 subjects (mean \pm SD age $23.8 \pm 2.2$ years) at doses of 0.3 and $0.6 \mathrm{mg}$ in comparison with two placebo conditions. Scopolamine at both doses produced marked sedation as rated by subjects and an observer. In the continuous performance test, vigilance was impaired by both doses of scopolamine. The span of apprehension test showed differing results (only the high dose of scopolamine showed a performance decrement only in the three-character version of the span of apprehension test). Significant impairment by both doses of scopolamine was seen in immediate and delayed free recall, continuous visual recognition, running word recognition and running picture recognition. While scopolamine caused a significant slowing in average reaction times for simultaneous matching as well as for delayed matching, subjects made more errors under scopolamine compared to placebo only in delayed matching, not in simultaneous matching. Also, the main outcome of matching to sample showed significant effects only in delayed
\end{abstract}

\section{KARGER}

Fax +41613061234

E-Mail karger@karger.ch

www.karger.com
(C) 2003 S. Karger AG, Basel

0302-282X/03/0482-0087\$19.50/0

Accessible online at:

www. karger.com/nps matching, not in simultaneous matching. Notable in this study is the incongruity between the simultaneous matching test and the span of apprehension test on the one hand and the other cognitive tests used on the other. These results demonstrated that scopolamine has a greater effect on memory than on attention. Thus, the scopolamine-induced effects in the present study seem to be more relevant to Alzheimer's disease in an advanced phase than to normal aging.

Copyright $\odot 2003$ S. Karger AG, Basel

\section{Introduction}

Two aspects of scopolamine action on cognition have been discussed controversially in recent years. The drug effect has been discussed as a model for memory deficits seen in patients with Alzheimer's disease [1] or a more general model for cognitive deficits associated with normal aging [2-5]. In a comprehensive battery of cognitive tasks, scopolamine was shown to produce the same deficits as normal aging [3]. Errors of intrusion, decreased digit span and impaired object naming, frequently found in patients with Alzheimer dementia, were not seen after different doses of scopolamine injections. Thus, it seems that scopolamine mimics some but not all relevant aspects of cognitive deficits seen in patients with early Alzheimer's disease. The question is, which aspects of normal aging
Dr. G. Koller

Department of Psychiatry, University of Munich, Nussbaumstrasse 7

DE-80336 München (Germany)

Tel. +49 8923 323660, Fax +498923 323671

E-Mail externe.heroinstudie.koller@muenchen.de 
are close to those observed after scopolamine administration. Callaway et al. [4] showed that scopolamine failed to impair performance in an age-sensitive task of rapid visual information processing (span of apprehension test).

Scopolamine has been shown to significantly lower stimulus sensitivity and to prevent the rise bias, which occurred in the placebo condition [6]. Some former studies demonstrated that there is a significant overall correlation between age and scopolamine effects on psychomotor speed, short-term recall, visual tracking speed, viso-motor coordination and sequencing ability [7]. These findings need further evaluation.

Furthermore, there has been discussion whether scopolamine effects are primarily in the domain of attention or of memory and if there is any causal relationship between both aspects of cognition [5, 8-11]. It has been argued that larger doses of scopolamine are required to impair memory performance than to produce decrements in arousal [12]. Coadministration of drugs with attentionenhancing effects like amphetamine or nicotine, however, did reverse scopolamine-induced memory deficits in free recall [13]. Scopolamine- or lorazepam-induced sedation (rated by the subject or measured by motor retardation) was found to be more closely related to performance on attention and psychomotor tasks than to performance on memory tasks [5]. In some studies, cholinergic drugs have been shown to have an effect on both attentional and memory aspects of information processing [14].

The matching to sample paradigm could be helpful in distinguishing the attentional and amnesic action of scopolamine in information processing. Performance on this task is particularly sensitive to damage of the medial temporal lobe, including those regions vulnerable to Alzheimer's disease [15]. The paradigm was first described in a scopolamine study with monkeys [16]. The animals were shown a 3-second illumination of one of nine panels on a three-by-three display. Following a variable delay, the animals were given access to the panel and were rewarded for a correct response. In humans, a slightly different version is used, which implies the presentation of several visual choice stimuli either simultaneously with a target stimulus (also called visual discrimination), immediately after the target stimulus has disappeared ( 0 s delay) or after longer delays, generally up to $30 \mathrm{~s}[17,18]$. The paradigm can be used in animal studies (nonmatching, e.g. pointing to the novel stimulus) as well as in human studies (matching, e.g. pointing to the sample stimulus). In several human studies, selective impairment by lorazepam [19] and by scopolamine $[3,8]$ in the delayed matching to sample task has been found, which is interpreted as an indicator of a selective amnesic action of both drugs.

In a recent study [20], it was shown that scopolamine can produce selective deficits in tests of short-term visual recognition memory that do not depend on overall impairment of arousal.

In humans, there is evidence that scopolamine impairs the acquisition of information and attentional functions as well as producing anterograde amnesia. The exact interrelationship between these effects is still unknown. Even less clear is the nature of the neural substrates for these different effects.

In this study, we examined the effects of scopolamine on memory and attention. We used the matching to sample paradigm for the measurement of scopolamine-induced deficits by the concurrent measurement of attention and memory with a battery of tests that have previously shown effects of scopolamine or lorazepam [10, $19,21,22]$. In this study, effects of scopolamine on memory were tested by immediate and delayed free recall, continuous visual recognition, running word recognition and running picture recognition. Effects on attention were tested by a continuous performance test and by a span of apprehension test. The matching to sample paradigm can be helpful in distinguishing attentional and memory effects. The selection of tests was guided by the question whether scopolamine-induced cognitive deficits in young subjects are similar to normal aging or to Alzheimer's disease, i.e. to test whether attentional and memory deficits are related or differently affected.

\section{Methods}

\section{Subjects}

Twelve healthy volunteers ( 8 females, 4 males; mean age $23.8 \pm$ 2.2 years; mean years of education $15.8 \pm 2.2$ ) participated in the study. Volunteers were intensively screened by a physical and psychiatric examination performed by an experienced psychiatrist to exclude those with medical or psychiatric illness. The body weight of the subjects ranged from 50 to $76 \mathrm{~kg}$ (mean $66.3 \pm 7.3 \mathrm{~kg}$ ). The subjects' intelligence was above average (mean Leistungsprüfsystem IQ [23] $124.5 \pm 9.6$ ), and so was their memory performance [mean number of words recalled in the first trial of the Auditory Verbal Learning Test (AVLT) was $10.2 \pm 2.1$, and in the fifth trial of the AVLT, it was $15.4 \pm 0.9$ ]. Average performance of the AVLT was performed $[24,25]$. The defined protocol was approved by the Faculty Medical Ethics Committee and all subjects signed informed consent prior to participation.

\section{Design and Dosing}

The study was double blind, randomized and used a Latin square design. Each subject received four subcutaneous injections (two pla- 
cebo injections, plus 0.3 and $0.6 \mathrm{mg}$ of scopolamine hydrobromide) at weekly intervals.

\section{Procedure}

On the screening day, subjects underwent a medical and psychological examination and a training session on the computerized task with items different from those used on the test day. On all of the four experimental days, however, the same items were used. Presentation time in the continuous performance test was generally $40 \mathrm{~ms}$. For subjects who had less than $75 \%$ hits on the screening day, presentation time was $70 \mathrm{~ms}$ on all experimental days. There was a further training session for the continuous performance test on each of the experimental days. Four word lists were used for free recall. The first word list was presented $3 \mathrm{~min}$ before drug injection. The second, third and fourth word lists were presented 82, 137 and 213 min after drug injection, respectively, one at a time (table 1). For visual acuity, subjects had to determine the position of a variable gap in automatically presented circles. At the end of each session, subjects and an observer were asked to judge if placebo or scopolamine had been applied. Item presentation and data collection were controlled by an IBM-compatible PC.

\section{Mood Assessment}

For mood evaluation, the 15 items of the EWL-G (Eigenschaftswörterliste; adjective check list) [26] and three further items (wakefulness, physical well-being, effectiveness) were presented on sevenpoint rating scales to subjects and to an observer. Answers were given on a seven-point rating scale between 'absolutely true' and 'absolutely not true'. Additionally, an observer rated the subjects' personality and test behavior (understanding of test instructions, willingness to continue, interest in own performance, cooperation, conscientiousness, motivation, self-criticism, stress resistance, nervousness, amount of complaining and ambition). The questions were the same for each test day.

\section{Attention}

Continuous Performance Test. The continuous performance test goes back to Rosvold et al. [27] and was reintroduced by Nuechterlein $[28,29]$ as a vigilance test. The continuous performance test measures sustained attention. Digits (0-9) are presented tachistoscopically on a screen against a noise background. Digits appear in a random sequence over $8 \mathrm{~min}$ and at a rate of one digit per second. The subjects are required to press a button whenever a particular target digit (the number zero) appears. A total of 120 target digits and 360 nontargets are presented. The nonparametric measure of sensitivity is used as a measure of outcome. We used A to designate the nonparametric measure of sensitivity for the continuous performance test.

Span of Apprehension Test. The procedure is adapted from that reported by Estes and Taylor [30]. The span of apprehension test is created to show effects on attention. This test is used to measure the number of items which a person can recognize at the same time. 80 sets of characters are consecutively shown for $100 \mathrm{~ms}$ each. Each set of characters consists of 3 or 8 characters and comprised either the character F or T, never both together. Subjects have to decide which of the two characters has been presented. Alternatively, 10 sets with three and 10 sets with 8 characters are shown over 8 min. ISI was $2 \mathrm{~s}$, but was prolonged occasionally until the subject pressed one of the two buttons. The percentage of hits is used as a measure of outcome.

Effects of Scopolamine on Cognitive

Functions
Table 1. Experimental schedule

\begin{tabular}{ll}
\hline Time (min) & Procedure \\
\hline-3 & Word list 1 \\
\pm 0 & Drug injection \\
+10 & Training of continuous performance test \\
+18 & Break \\
+58 & Learning trial of running word recognition \\
+68 & Learning trial of running picture recognition \\
+82 & Word list 2 \\
+85 & Break \\
& Block 1 \\
+90 & Mood evaluation \\
+92 & Running word recognition \\
+96 & Running picture recognition \\
+103 & Simultaneous matching \\
+105 & Delayed matching \\
+113 & Continuous visual memory \\
+122 & Break \\
+137 & Word list 3 \\
+140 & Visual acuity \\
+143 & Continuous performance test \\
+151 & Span of apprehension test \\
+159 & Mood evaluation by an observer \\
+159 & Break \\
& Block 2 \\
+179 & Mood evaluation \\
+181 & Running word recognition \\
+185 & Running picture recognition \\
+192 & Simultaneous matching \\
+194 & Delayed matching \\
+202 & Continuous visual memory \\
+211 & Delayed free recall of word lists 1-3 \\
+213 & Word list 4 \\
+216 & Test behavior evaluation by an observer \\
+223 & Side effect evaluation \\
&
\end{tabular}

\section{Memory}

Immediate and Delayed Free Recall. Four lists of 24 new words each are matched for frequency of occurrence in the German language, word length and imagery. The lists were read before injection and 80, 140 and $210 \mathrm{~min}$ after injection. The same word lists were used every test day. The words are read aloud at a rate of one word every $2 \mathrm{~s}$. Immediate written recall in any order is required. The difference between total correct recall and omission errors is used as a measure of outcome for free recall. For delayed free recall, subjects are asked to write in any order as many of the words as they could remember from the first three lists (table 1). The number of correctly remembered words from each list is used as a measure of outcome for delayed free recall (table 1).

Continuous Visual Recognition. The continuous visual recognition task is a memory test. In each test block, a new list of 108 pictures is presented continuously on the screen. In each list, 18 target stimuli appear for a second time. The interval between the first and 
second presentation of the target stimuli varies between 10 and 20 items. The target stimuli are spread over the whole list. For each target stimulus, four distractors are constructed with decreasing similarity to the target stimulus. One to four distractors are presented only after the first presentation of the corresponding target stimulus and before the second presentation of the target stimulus. Each item is presented on the screen for up to $10 \mathrm{~s}$ or until subjects press one of the two buttons (item presented for the first or for the second time), whichever comes first. Hits minus false alarms were used as a measure of outcome.

Running Word Recognition. The running word recognition test measures memory effects. Two hundred nouns with a frequency of usage greater than 1: 110.000 [28] were selected and randomly allocated to a preliminary list and two test lists. The 50 new words in each list are mixed with 50 old words from the preceding list. Thus, in each block, 100 words are presented visually for a maximum of $6 \mathrm{~s}$. The subject's task is to classify each word as 'old' or 'new'. Hits minus false alarms were used as the measure of outcome.

Running Picture Recognition. The running picture recognition test measures memory effects. The structure of the running picture test is the same as for running word recognition. For test construction, 200 different pictures are used. Both running recognition tasks as well as the matching to sample tasks are part of the Computerisierte Gedächtnis und Aufmerksamkeitstest (München) [CGT-(M)], an automated memory test.

\section{Matching to Sample}

This test consists of four parallel matching to sample tasks $(2 \times$ simultaneous matching to sample, $2 \times$ delayed matching to sample), each consisting of 18 items. Each item consists of a target stimulus and a set of four simultaneously presented, numbered choice stimuli (one target stimulus and three distractors). Target stimuli consist of motivating abstract and realistic colored pictures $(60 \times 60 \mathrm{~mm})$, and the distractors differ from target stimuli to some degree in color, size or content. Each item is presented on the screen for up to $20 \mathrm{~s}$ or until subjects press the correct button, whichever comes first. If the response is an error, the item remains on the screen and subjects can choose again. In the simultaneous matching task, the 18 items consist of a target stimulus in the left half of the screen and four choice stimuli on the right. In the delayed matching task, a target stimulus is shown for $4 \mathrm{~s}$, followed by $15 \mathrm{~s}$ of tone distraction. For tone distraction, high $(700-\mathrm{Hz})$ and low $(300-\mathrm{Hz})$ tones with a duration of $250 \mathrm{~ms}$ and ISI of $800-3,000 \mathrm{~ms}$ are presented at an average ratio of 1.2 . Subjects are instructed to react to the tones. Then the four choice stimuli are presented simultaneously and subjects are requested to press the corresponding button as quickly as possible. For matching to sample tasks, median reaction time to correct response, errors and points are calculated. Points are computed a priori as follows: for a correct response during the first second, 30 points were given, for a correct response during the following second, 29 points were given. A correct response on the second key press received a score 10 points lower. A correct response on the third, fourth or fifth key press received 0 points. Thus, a fast and correct response received the highest number of points.

\section{Statistical Analyses}

For the main analysis of treatment effects, the results of tests performed 58-216 min after drug intake were averaged. These data were subjected to analyses of variance. The design was that of a Latin square factorial design, testing the effects of drugs and test days. The following post hoc comparisons were calculated: placebo 1 versus placebo 2; low-dose scopolamine versus mean placebo; high-dose scopolamine versus mean placebo, and high-dose scopolamine versus low-dose scopolamine. The statistical significance of these post hoc comparisons was corrected using Bonferroni adjustment, i.e. by dividing the nominal significance level by the number of comparisons. The result of post hoc comparisons is reported as statistically significant only when $\mathrm{p}<0.0125$.

\section{Results}

The effects of scopolamine on visual acuity were not statistically significant $\left(\mathrm{F}_{(3,24)}=0.8 ; \mathrm{p}=0.483\right)$. All subjects and an observer were perfectly able to distinguish between placebo and verum on all study days (100\% correct guessing). There were no significant differences between the two placebo conditions for any of the measures. All results are shown in table 2.

\section{Mood Evaluation}

Scopolamine caused a marked sedation on self-rating and even more on observer rating of mood, when compared to placebo. Generally, there were main drug effects for 14 items in self-ratings of mood and 23 items for observer ratings of mood, where most items dealt with a reduction of alertness, effectiveness, concentration and cheerfulness and an increase in social withdrawal. The most affected single item on self-rating and observer rating was drowsiness.

\section{Attention}

Continuous Performance Test. Vigilance was impaired under both doses of scopolamine in comparison with placebo. The results for scopolamine $0.3 \mathrm{mg}$ versus placebo reached significance, as did those for scopolamine $0.6 \mathrm{mg}$ placebo ( $\mathrm{p}<0.01$ each).

Span of Apprehension Test. In comparison with placebo, only the high dose of scopolamine $(0.6 \mathrm{mg})$ produced a performance decrement in the three-character, but not in the eight-character version of the task $(p<0.05)$.

\section{Memory}

Immediate and Delayed Free Recall. In immediate free recall as well as delayed free recall, there was a significant difference between scopolamine $0.3 \mathrm{mg}$ and placebo as well as scopolamine $0.6 \mathrm{mg}$ and placebo $(\mathrm{p}<0.001 \mathrm{each})$. Differences were shown between the 4 word lists used. While there were no drug-related differences in the immediate recall of the first word list $\left(\mathrm{F}_{(3,24)}=0.0 ; \mathrm{p}=0.997\right)$, immediate recall was markedly reduced in the drug-active 
Table 2. Effects of scopolamine on sedation, attention, memory and matching to sample

\begin{tabular}{|c|c|c|c|c|c|c|c|c|c|c|c|c|c|}
\hline & \multirow[t]{2}{*}{ Placebo 1} & \multirow[t]{2}{*}{ Placebo 2} & \multirow[t]{2}{*}{ p1 } & \multirow{2}{*}{\multicolumn{2}{|c|}{$\begin{array}{l}\text { Scopolamine } \mathrm{p} 2 \\
0.3 \mathrm{~g}\end{array}$}} & \multirow{2}{*}{$\begin{array}{l}\text { Scopolamine } \\
0.6 \mathrm{~g}\end{array}$} & \multirow{2}{*}{ p3 } & \multirow[t]{2}{*}{$\mathrm{p} 4$} & \multicolumn{2}{|c|}{ Factor drug } & \multicolumn{2}{|l|}{ Day } & \multirow{2}{*}{$\begin{array}{l}\text { Retest } \\
\text { reliability }\end{array}$} \\
\hline & & & & & & & & & $\mathrm{F}(3,24)$ & $\mathrm{p}$ & $\mathrm{F}(3,24)$ & $p$ & \\
\hline \multicolumn{14}{|l|}{ Sedation $^{1}$} \\
\hline Self-rating of sedation & $2.8(0.8)$ & $3.1(1.0)$ & NS & $4.8(1.2)$ & $* * *$ & $5.1(0.6)$ & $* * *$ & NS & 25.8 & $<0.001$ & 1.3 & NS & 0.38 \\
\hline Observer rating of sedation & $2.5(1.1)$ & $2.9(0.7)$ & NS & $4.7(1.1)$ & $* * *$ & $6.2(0.5)$ & $* * *$ & $* * *$ & 63.3 & $<0.001$ & 2.4 & NS & 0.48 \\
\hline \multicolumn{14}{|l|}{ Attention } \\
\hline $\mathrm{CPT}(\mathrm{A})$ & $0.91(0.06)$ & $0.92(0.08)$ & NS & $0.84(0.08)$ & $* *$ & $0.84(0.11)$ & $* *$ & NS & 6.9 & 0.002 & 5.6 & 0.005 & 0.80 \\
\hline SAT $3, \%$ hits & $94.8(4.9)$ & $94.1(5.4)$ & NS & $92.7(5.6)$ & NS & $90.8(6.2)$ & $*$ & NS & 3.6 & 0.027 & 3.8 & 0.024 & 0.39 \\
\hline SAT $8, \%$ hits & $80.8(11.5)$ & $81.5(8.4)$ & NS & $82.0(7.4)$ & NS & $76.8(10.9)$ & NS & NS & 1.5 & NS & 2.4 & NS & 0.39 \\
\hline \multicolumn{14}{|l|}{ Memory } \\
\hline Immediate free recall (correct) & $12.2(2.4)$ & $11.5(3.8)$ & NS & $9.1(3.6)$ & $* * *$ & $5.9(2.7)$ & $* * *$ & $* * *$ & 26.2 & $<0.001$ & 8.8 & $<0.001$ & 0.64 \\
\hline Delayed free recall (correct) & $6.8(3.2)$ & $6.1(2.8)$ & NS & $4.4(3.3)$ & $* * *$ & $3.3(1.6)$ & $* * *$ & $*$ & 19.8 & $<0.001$ & 14.6 & $<0.001$ & 0.92 \\
\hline Visual recognition (hits - FA) & $0.38(5.5)$ & $1.16(5.1)$ & NS & $-1.37(5.9)$ & NS & $-5.12(8.8)$ & $* * *$ & $* *$ & 10.6 & $<0.001$ & 30.0 & $<0.001$ & 0.79 \\
\hline Word recognition (hits - FA) & $19.7(6.8)$ & $20.3(4.0)$ & NS & $17.2(6.0)$ & NS & $11.5(4.7)$ & $* * *$ & $* *$ & 11.2 & $<0.001$ & 2.2 & NS & 0.56 \\
\hline Picture recognition (hits - FA) & $31.0(6.1)$ & $30.1(4.6)$ & NS & $27.6(4.8)$ & $* *$ & $21.9(5.6)$ & $* * *$ & $* * *$ & 24.6 & $<0.001$ & 12.0 & $<0.001$ & 0.52 \\
\hline \multicolumn{14}{|l|}{ Matching to sample } \\
\hline Simultaneous, $\mathrm{s}$ & $2.4(0.7)$ & $2.4(0.3)$ & NS & $2.5(0.6)$ & NS & $3.1(0.5)$ & $* * *$ & $* * *$ & 11.5 & $<0.000$ & 14.9 & $<0.000$ & 0.56 \\
\hline 15-second delayed, s & $2.5(0.9)$ & $2.3(0.5)$ & NS & $2.7(0.7)$ & NS & $3.2(0.7)$ & $* * *$ & $*$ & 6.1 & 0.003 & 7.8 & 0.001 & 0.72 \\
\hline Simultaneous, errors & $1.8(1.0)$ & $1.6(1.3)$ & NS & $2.4(1.4)$ & NS & $2.0(1.5)$ & NS & NS & 1.1 & NS & 0.4 & NS & 0.60 \\
\hline 15 -second delayed, errors & $3.9(1.9)$ & $4.0(1.8)$ & NS & $8.0(3.2)$ & $* *$ & $6.4(2.3)$ & $* *$ & NS & 6.0 & 0.003 & 1.0 & NS & 0.65 \\
\hline Simultaneous, points & $475.3(18.4)$ & $475.3(23.6)$ & NS & $469.9(17.9)$ & NS & $460.6(21.6)$ & $*$ & NS & 2.6 & NS & 8.8 & 0.001 & 0.46 \\
\hline 15 -second delayed, points & $453.9(27.7)$ & $450.6(39.6)$ & NS & $427.2(30.2)$ & $* *$ & $416.6(25.3)$ & $* * *$ & NS & 8.1 & 0.001 & 5.2 & 0.007 & 0.83 \\
\hline
\end{tabular}

Values are group means (SD in parentheses), ANOVA results and retest reliability of measures. Asterisks indicate the uncorrected significance of the four comparisons: placebo 1 versus placebo 2 (p1), scopolamine $0.3 \mathrm{mg}$ versus mean placebo (p2), scopolamine $0.6 \mathrm{mg}$ versus mean placebo (p3), and scopolamine $0.3 \mathrm{mg}$ versus scopolamine $0.6 \mathrm{mg}(\mathrm{p} 4) .{ }^{*} \mathrm{p}<0.05,{ }^{* *} \mathrm{p}<0.01,{ }^{* * *} \mathrm{p}<0.001$. None of the interactions was significant. NS $=$ Not significant; CPT $=$ continuous performance test; SAT $=$ span of apprehension test; $\mathrm{FA}=$ false alarms.

1 The following items with seven-point scales were combined into a single score $(1=$ no sedation): widely awake, very effective, very active, very attentive, not sluggish, not exhausted, not drowsy, and not dreamy.

time for word list $2\left(\mathrm{~F}_{(3,24)}=20.4 ; \mathrm{p}<0.001\right)$ and word list $4\left(\mathrm{~F}_{(3,24)}=23.2 ; \mathrm{p}<0.01\right)$. In addition, there was a main effect of scopolamine on delayed recall. $211 \mathrm{~min}$ after intake of either 0.3 or $0.6 \mathrm{mg}$ of scopolamine, subjects recalled on average 1.2 and 0.7 words more, respectively, from the first word list learned 3 min before drug injection than under placebo. This effect of retrograde hypermnesia, however, failed to reach significance $4\left(\mathrm{~F}_{(3,24)}=1.0 ; \mathrm{p}<\right.$ $0.405)$. These results are shown in figure 1.

Continuous Visual Recognition. There was a main effect of drug condition on this measure. Subsequent contrasts only showed a reduced performance under the high dose of scopolamine. Main drug effects for the first block $\left(\mathrm{F}_{(3,24)}=6.3 ; \mathrm{p}<0.003\right)$ were comparable to those of the second block $\left(\mathrm{F}_{(3,24)}=6.0 ; \mathrm{p}<0.003\right)$.

Running Word Recognition. Again there was a main effect of drug condition on this task and a reduced performance only under the high dose of scopolamine. Main drug effects in this task were higher in the second block $\left(\mathrm{F}_{(3,24)}=10.6 ; \mathrm{p}<0.01\right)$ than in the first block $\left(\mathrm{F}_{(3,24)}=\right.$ $4.4 ; \mathrm{p}<0.013)$.

Running Picture Recognition. There was a marked decrement by both doses of scopolamine in this task in comparison with placebo. Again, main drug effects in this measure were higher in the second block $\left(\mathrm{F}_{(3,24)}=11.5\right.$; $\mathrm{p}<0.01)$ than in the first block

\section{Matching to Sample}

While scopolamine caused a significant slowing of average reaction times for simultaneous matching $\left(F_{(3,24)}=11.5 ; p<0.01\right)$ and for delayed matching $\left(F_{(3,24)}=6.1 ; p<0.003\right)$, subjects made more errors only on delayed matching under scopolamine compared to placebo $\left(\mathrm{F}_{(3,24)}=1.1 ; \mathrm{p}<0.353\right)$. In the main outcome measure, a combination of speed and accuracy of response, there was again a main effect of drug in delayed matching only $\left(\mathrm{F}_{(3,24)}=8.1 ; \mathrm{p}<0.001\right)$, but not in simultaneous matching $\left(\mathrm{F}_{(3,24)}=1.1 ; \mathrm{p}<0.353\right)$. Main drug effects for simultaneous matching and for delayed matching were somewhat higher in the second test block as compared to the first test block. Retest reliability under both placebo conditions was generally higher for delayed matching as compared to simultaneous matching. This effect was marked for points, where reliability was $\mathrm{V}_{\mathrm{t}}=0.83$ for delayed matching, but only $\mathrm{V}_{\mathrm{t}}=0.46$ for simultaneous matching. 
Fig. 1. Recall of 24-word lists (lists 1-3) under placebo 1 , placebo $2,0.3 \mathrm{mg}$ of scopolamine and $0.6 \mathrm{mg}$ of scopolamine.

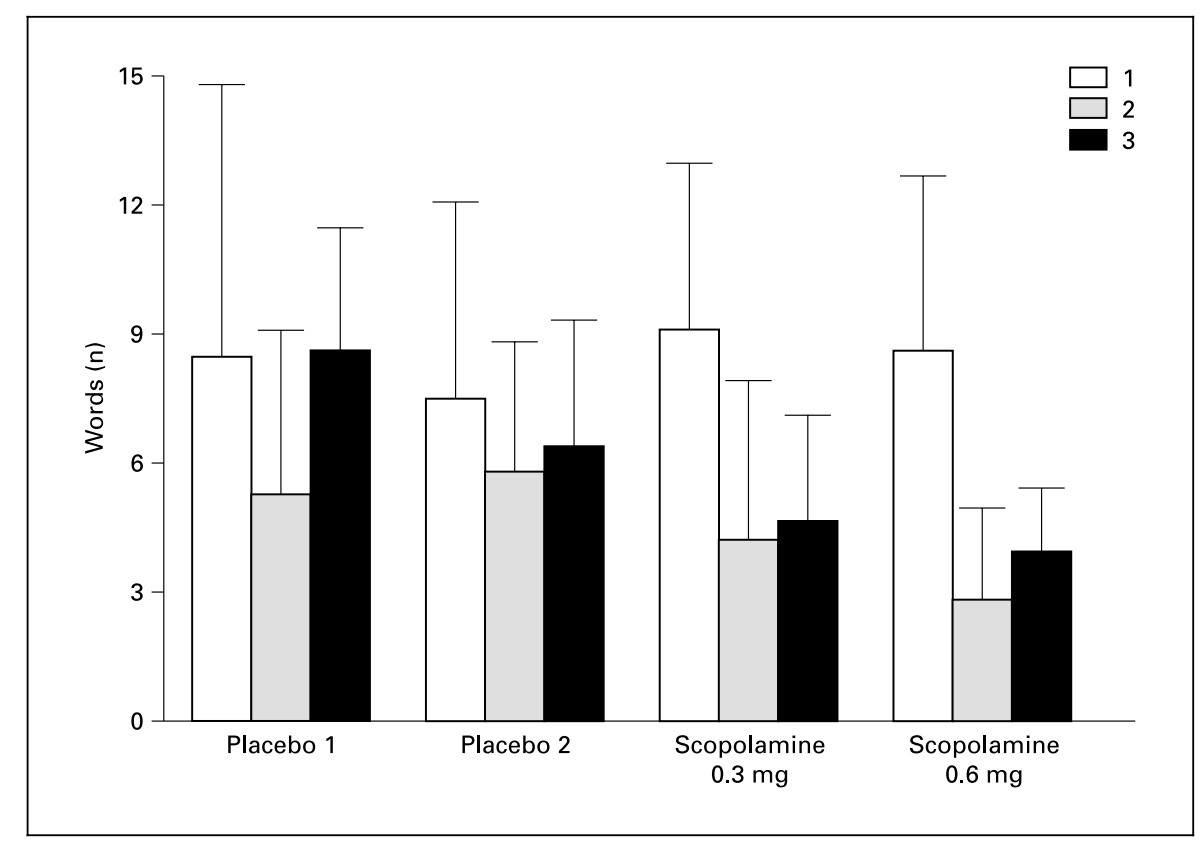

\section{Discussion}

In this study, scopolamine produced profound sedation, a marked and general reduction in memory performance and a decrement in vigilance. Performance on the span of apprehension test was only marginally affected and no impairment was noted with respect to the accuracy measure of the simultaneous matching task. While scopolamine slowed reaction time on both matching tasks, accuracy was reduced in the delayed matching task only. A dose dependency was seen for all five control memory tests, for reaction time in both matching tasks and for observer rating of mood.

Memory impairment was recognized in both running recognition tests. There was more impairment in the second test block compared to the first test block.

Immediate recall was markedly reduced for the word list at times 2 and 4. Results for free recall and most other cognitive tests imply that the effects of scopolamine were only slightly more pronounced in the second test block. The drug-active time of scopolamine is $1-2.5 \mathrm{~h}$ after drug injection. The effect of retrograde hypermnesia in the memory test was not statistically significant.

In this study, scopolamine only had a marginal effect in the three-character version of the span of apprehension test. There was nearly no effect on the eight-character version of the span of apprehension test. The span of apprehension test is a test of attentional response. A nonsignifi- cant decrease of mean matrix size in an adaptive age-sensitive version of the span of apprehension test under $1.2 \mathrm{mg}$ of oral scopolamine in contrast to placebo from a predrug score of 9.6 numerals to a postdrug score of 9.2 numerals has been reported elsewhere [4]. This leads to the conclusion that normal aging does impair detection of targets for eight and more characters. This can lead to the assumption that the observed effects of scopolamine in our study are different from those of normal aging. However, the span of apprehension test is not known to be very sensitive to drug-induced impairments.

A significant slowing of reaction time in simultaneous matching by scopolamine was shown. There was a main effect of the drug in delayed matching but not in simultaneous matching. Opposite to these findings, scopolamine was shown in another study to produce deficits on tests of verbal recall, visuospatial recall, visual recognition memory, visuospatial practice, visuoperceptual function and psychomotor speed [3]. Immediate memory, language function, object sorting and frequency of intrusion errors were unaffected [3]. Reanalyses of previous studies show that pro- and anticholinergic drugs influence initial discriminative ability in delayed matching to sample performance. This was recognized to be the same effect as shown by patients with Alzheimer's disease [32].

In congruence with previous research, scopolamine caused sedation $[5,10,33]$ in the field of mood evaluation. Scopolamine reduced performance on the contin- 
uous performance task, as shown previously [8], and affected memory. In this study, memory effects were shown by the immediate and delayed memory test, running word recognition, running picture recognition and continuous visual recognition. All these tests are sensitive to memory effects. In our results, scopolamine seems to show clearer effects in other memory tasks used than in the matching to sample paradigm.

In the literature, cholinergic activity has been shown to produce a consistent pattern of deficits. Scopolamine is known to produce impairments in long-term memory for items no longer in the consciousness [2, 34, 35].

Also, in the field of attention, simultaneous matching failed to show the deficits found in the continuous performance test. In this study, the simultaneous matching task was easier and less reliable than the delayed matching task. Another psychometric problem is the appropriate outcome measure for matching tasks. Memory functions are generally expressed in terms of accuracy. For attentional functions, reaction time of accuracy under speed conditions is frequently used. In this study, we used a combination of speed and accuracy as a main outcome measure and presented data for reaction time and errors separately. Since reaction time was markedly reduced under scopolamine, this leads to conflicting results and raises the question what is really measured by matching to sample tasks.

Retrograde hypermnesia for items learned before scopolamine injection in comparison with placebo was not found in the present study. The lack of retrograde hypermnesia under scopolamine was also found previously [36] and makes a selective memory impairment due to scopolamine less probable.

Perhaps the matching to sample paradigm is not a powerful tool to distinguish between memory and nonmemory effects of drugs, at least in human studies. The reason is probably an inherent confounding of task type and task difficulty. It remains to be seen if the inclusion of more items or more complex items, especially in the simultaneous part of the paradigm, or shorter presentation times might overcome this problem.

In the literature, effects of scopolamine seem to be quite specific in nature. Scopolamine is described to produce selective deficits in tests of short-term visual recognition memory recognized by the matching to sample test [20]. These effects may have implications for the pharmacological modeling of dementia and memory disorders. Scopolamine-induced effects were shown to be produced delay dependent [37]. Selective effects of scopolamine on matching to sample tasks have been described with a maximum 12-second delay [20]. Differences from our results may be due to different times of delay. This shows scopolamine effects to be very specific and to need further evaluation.

In tests detecting attention, impairment of both speed and accuracy induced by scopolamine has been described $[6,13]$. We were able to confirm these results by using different kinds of tests measuring attention. This shows that different kinds of tests measuring attention are differently sensitive to scopolamine effects.

Cholinergic blockade by scopolamine produces significant impairment in long-term memory [2]. There is a pattern of different effects of scopolamine on short-term memory tasks. On the Brown-Peterson memory task, reduced performance has been shown [8]. Rusted and Warbuton [35] also reported scopolamine-induced deficits in performance on short-term memory tasks. These results seem to be compatible with the model of working memory [16]. Separable components of immediate memory are described to be responsible for distinct functions. According to the hypothesis of Rusted and Warbuton [38], scopolamine impairs the central executive component of working memory as shown by the immediate and free recall task. These results are confirmed by our results.

The results of the present study indicate a scopolamine-induced reduction in both cognitive functions, attention and memory, that was only partially shown by the matching tasks. Of course, drug effects on memory cannot be separated from drug effects on attention with definite precision. However, some tests are known to be more sensitive for memory effects than attention effects, for example word lists, running word and running picture recognition or continuous visual recognition.

None of the tests used can be considered very specific either for Alzheimer's disease or for normal aging. We can confirm results shown in the literature that scopolamine is more effective in delayed than in simultaneous matching, which is shown to be more specific for Alzheimer's disease [32].

The small number of subjects and the lack of various delays for delayed matching limit the generalizability of the findings. More conclusive results will be reached by the use of tasks which are carefully matched for psychometric properties including sensitivity to change.

Attention and memory are very closely related. Without attention, a normal working memory is not possible. Because in our results the tests used were very similar (matching to sample paradigm with and without delay), we can conclude that scopolamine mainly has very strong effects on memory besides its effects on attention. 
There are not too many differences in psychometric profiles between aging and the early phase of Alzheimer dementia. In both cases, there are deficits in attention as well as in memory.

In the advanced state of Alzheimer dementia, psychometric profiles become more and more different from those in normal aging, as memory functions get worse in
Alzheimer disease. In our results, scopolamine shows strong effects which are too strong for normal aging. Effects shown by scopolamine in our data are more pronounced on memory, so that we can conclude that the scopolamine model is closer to Alzheimer dementia than to normal aging.

\section{References}

1 Weingartner H: Models of memory dysfunctions. Ann NY Acad Sci 1985;444:359-369.

2 Drachman DA, Leavitt J: Human memory and the cholinergic system. A relationship to aging? Arch Neurol 1974;30:113-121.

3 Flicker C, Serby M, Ferris SH: Scopolamine effects on memory, language, visuospatial praxis and psychomotor speed. Psychopharmacology (Berl) 1990;100:243-250.

4 Callaway E, Halliday R, Naylor H, Schechter G: Effects of oral scopolamine on human stimulus evaluation. Psychopharmacology (Berl) 1985;85:133-138.

5 Curran HV, Schifano F, Lader M: Models of memory dysfunction? A comparison of the effects of scopolamine and lorazepam on memory, psychomotor performance and mood. Psychopharmacology (Berl) 1991;103:83-90.

6 Wesnes K, Warburton DM: Effects of scopolamine on stimulus sensitivity and response bias in a visual vigilance task. Neuropsychobiology 1983;9:154-157.

7 Tariot PN, Patel SV, Cox C, Henderson RE: Age-related decline in central cholinergic function demonstrated with scopolamine. Psychopharmacology (Berl) 1996;125:50-56.

8 Caine ED, Weingartner H, Ludlow CL, Cudahy EA, Wehry S: Qualitative analysis of scopolamine-induced amnesia. Psychopharmacology (Berl) 1981;74:74-80.

9 Dunne MP, Hartley LR: The effects of scopolamine upon verbal memory: Evidence for an attentional hypothesis. Acta Psychol (Amst) 1985;58:205-217.

10 Newhouse PA, Sunderland T, Tariot PN, Weingartner H, Thompson K, Mellow AM, Cohen RM, Murphy DL: The effects of acute scopolamine in geriatric depression. Arch Gen Psychiatry 1988;45:906-912.

11 Sahakian BJ, Downes JJ, Eagger S, Evenden JL, Levy R, Philpot MP, Roberts AC, Robbins TW: Sparing of attentional relative to mnemonic function in a subgroup of patients with dementia of the Alzheimer type. Neuropsychologia 1990;28:1197-1213.

12 Broks P, Preston GC, Traub M, Poppleton P, Ward C, Stahl SM: Modelling dementia: Effects of scopolamine on memory and attention. Neuropsychologia 1988;26:685-700.
13 Wesnes K, Revell A: The separate and combined effects of scopolamine and nicotine on human information processing. Psychopharmacology (Berl) 1984;84:5-11.

14 Warburton DM, Wesnes K: Drugs as research tools in psychology: Cholinergic drugs and information processing. Neuropsychobiology 1984;11:121-132.

15 Mishkin M, Appenzeller T: The anatomy of memory. Scientific American, June, 1987, pp 80-89.

16 Bartus RT, Johnson HR: Short-term memory in the rhesus monkey: Disruption from the anti-cholinergic scopolamine. Pharmacol Biochem Behav 1976;5:39-46.

17 Dunnett SB: Comparative effects of cholinergic drugs and lesions of nucleus basalis or fimbriafornix on delayed matching in rats. Psychopharmacology (Berl) 1985;87:357-363.

18 Beninger RJ, Wirsching BA, Jhamandas K, Boegman RJ: Animal studies of brain acetylcholine and memory. Arch Gerontol Geriatr Suppl 1989;1:71-89.

19 Satzger W, Engel RR, Ferguson E, Kapfhammer H, Eich FX, Hippius H: Effects of single doses of zolpidem, lorazepam, and placebo on memory and attention in healthy young and elderly volunteers. Pharmacopsychiatry 1990; 23(suppl 3):114-119.

20 Robbins TW, Semple J, Kumar R, Truman MI, Shorter J, Ferraro A, Fox B, McKay G, Matthews K: Effects of scopolamine on delayedmatching-to-sample and paired associates tests of visual memory and learning in human subjects: Comparison with diazepam and implications for dementia. Psychopharmacology (Berl) 1997;134:95-106.

21 Clark EO, Glanzer M, Turndorf $\mathrm{H}$ : The pattern of memory loss resulting from intravenously administered diazepam. Arch Neurol 1979;36: 296-300.

22 Sold M, Lindner H, Weis KH: Effect of fentanyl, diazepam and flunitrazepam on memory function. A pharmacopsychologic study (in German). Anaesthesist 1983;32:519-524.

23 Horn W: Das Leistungsprüfsystem (L-P-S). Göttingen, Hogrefe, 1962.

24 Mitrushina MN, Boone KB, D'Elia LF: Handbook of Normative Data for Neuropsychological Assessment. New York, Oxford University Press, 1999.

25 Satzger W, Engel RR: Der computerisierte Gedächtnis und Aufmerksamkeitstest (München), CGT-M. Weinheim, Beltz, 1996.
26 Rösler F, Baumann U, Marake H: Zum Vergleich zwischen globaler und additiver Befindlichkeitsmessung. Diagnostica 1980;26:151164.

27 Rosvold HE, Mirsky A, Sarason I, Bransome ED Jr, Breck LH: A continuous performance test of brain damage. J Consult Psychol 1956; 20:343-350.

28 Nuechterlein KH, Parasuraman R, Jiang Q: Visual sustained attention: Image degradation produces rapid sensitivity decrement over time. Science 1993;220:327-329.

29 Nuechterlein KH: Vigilance in schizophrenia and related disorders; in Steinhauser SR, Gruzelier JH, Zubin J (eds): Handbook of Schizophrenia, vol 5: Neuropsychology, Psychophysiology and Information Processing. Amsterdam, Elsevier, 1991, pp 397-433.

30 Estes WK, Taylor HA: A detection method and probabilistic models for assessing information processing from brief visual displays. Proc Natl Acad Sci USA 1964;52:446-454.

31 Meier H: Deutsche Sprachstatistik. Hildesheim, Georg Olms, 1964, Bd. 2.

32 White KG, Ruske AC: Memory deficits in Alzheimer's disease: The encoding hypothesis and cholinergic function. Psychon Bull Rev 2002;9: 426-437.

33 Safer DJ, Allen RP: The central effects of scopolamine in man. Biol Psychiatry 1971;3:347355.

34 Crow TJ, Grove-White IG: An analysis of the learning deficit following hyoscine administration in man. Br J Pharmacol 1973;49:322327.

35 Rusted JM, Warbuton DM: Effects of scopolamine on working memory of healthy young adults. Psychopharmacology 1988;96:487492.

36 Ghoneim MM, Mewaldt SP: Studies on human memory: The interactions of diazepam, scopolamine, and physostigmine. Psychopharmacology (Berl) 1977;52:1-6.

37 Hironaka N, Miyata H, Ando K: Effects of psychoactive drugs on short term memory in rats and rhesus monkeys. Jpn J Pharmacol 1992;59: 113-120.

38 Rusted JM, Warburton DM: Cognitive models and cholinergic drugs. Neuropsychobiology 1989;21:31-36. 